\title{
EMPREGABILIDADE DOS EGRESSOS TECNÓLOGOS DO CURSO DE ANÁLISE E DESENVOLVIMENTO DE SISTEMAS NOS INSTITUTOS FEDERAIS MINEIROS
}

\author{
Giuliano Viana de Alkmim ${ }^{1}$, Rosemary Dore Heijmans ${ }^{2}$ \\ ${ }^{1}$ Instituto Federal do Norte de Minas Gerais - Campus Januária Fazenda São Geraldo, \\ s/n, Km 6 - CEP 39480-000 - Januária / MG \\ ${ }^{2}$ Universidade Federal de Minas Gerais - Faculdade de Educação, Depto. de Ciências \\ Aplicadas à Educação - Sala 1606, Av. Antonio Carlos 6627 - BH-MG CEP 31270-901 \\ giuviana@gmail.com, rosemarydore@gmail.com

\begin{abstract}
This research aimed to analyze the process of inserting and maintaining of the graduates in the Higher Technology Course in Analysis and System Development (CST in ADS) in the labor market. This research was conducted with the technologists graduates of that course in the Federal Institutes (IFs) of Minas Gerais where there were graduates. It was performed through the electronic questionnaire and semi-structured interviews. The results showed that the technologist formed in CST in ADS, in (IFs) miners, who were part of the study, get a large insertion/maintenance in the labor market, as it was proved that the employment rate of this technologists is high.
\end{abstract} \\ Resumo: Esta pesquisa teve como objetivo analisar o processo de inserção e \\ manutenção do egresso do Curso Superior de Tecnologia em Análise e \\ Desenvolvimento de Sistemas (CST em ADS) no mundo do trabalho. Esta \\ investigação foi realizada com os egressos Tecnólogos do referido curso nos \\ Institutos Federais (IFs) Mineiros onde existiam alunos formados. A pesquisa \\ foi realizada com aplicação de questionário eletrônico e de entrevista \\ semiestruturada. Os resultados obtidos evidenciaram que o tecnólogo \\ formado no CST em ADS, nos (IFs) mineiros que fizeram parte do estudo, \\ consegue grande inserção/manutenção no mundo do trabalho, pois, ficou \\ provado que, o indice de empregabilidade desse tecnólogo é alto.
}

\section{INTRODUÇÃO}

Atualmente, a formação de tecnólogo é muito enfatizada no Brasil, como meio para preparar os jovens para uma inserção mais rápida no mercado de trabalho. No entanto, não existem pesquisas, de tecnólogos, nos Institutos Federais, na área de informática, voltadas para identificar como os egressos desses cursos percebem suas experiências e quais são as tensões vivenciadas na sua prática profissional, indicando como se concretizaram suas expectativas quanto ao relacionamento da educação profissional com o mercado de trabalho, assim como, os principais motivos de escolha dessa modalidade de ensino nos IFs mineiros, o local de sua atuação e os principais fatores que fazem diferença para que o esse tecnólogo consiga os maiores salários.

O CST em ADS, segundo o SISTEC, 2013, é o curso que representa a maior demanda de matrícula entre os cursos superiores de tecnologia nos IFs brasileiros. A diferença na quantidade de matrículas entre o CST em ADS e o segundo curso da modalidade, o Curso de Gestão Ambiental, é de praticamente 100\%. Apesar do grande 
interesse dos IFs no CST em ADS, não existe um estudo e praticamente nenhum acompanhamento sobre o seus egressos.

O artigo busca responder se os CST são planejados conforme as demandas: do mundo do trabalho; das particularidades da região onde a instituição de ensino, que oferta tais cursos, está inserida. Visa, ainda, saber se o seus egressos estão conseguindo um boa empregabilidade. Em linhas gerais, espera-se que este estudo possa oferecer melhor compreensão sobre os CST e o perfil do profissional por eles formado.

\section{A EMPREGABILIDADE}

Existem diferentes concepções sobre o termo empregabilidade, porém, há, entretanto, um elemento comum: a educação. Esta é destacada como fator fundamental para a aquisição de conhecimentos de que o indivíduo necessita para se manter ativo no mundo do trabalho.

A relação mais forte entre educação, trabalho e indivíduo contribuiu para direcionar as políticas públicas da educação nacional para uma proposta de formação influenciada pela noção de empregabilidade, bem como para a retomada do debate sobre a Teoria do Capital Humano; qual teve como principal representante Theodore Shultz.

O principal aspecto da teoria de Schultz (1973), um dos maiores expoentes da Teoria do Capital Humano, é o de que o indivíduo que investe em si mesmo (em capital humano) consegue ampliar as suas escolhas por um posto de trabalho. Entretanto, a teoria do capital humano, segundo o mesmo autor, valoriza o processo de aprendizagem e treinamento que também acontece fora do ambiente escolar, através da experiência de trabalho e da migração (quantidade de serviços).

Além do Capital Humano, existem outros fatores que são tomados como paradigmas para analisar a empregabilidade do indivíduo: o Capital Cultural e o Capital Social [HELAL, 2005]. Este formulado por Pierre Bourdieu e por James Coleman; aquele, somente por Bourdieu.

O Capital Cultural, caracteriza, por exemplo, a interferência do ambiente familiar em seus gostos e até mesmo em seu processo de socialização, bem como em sua trajetória de aprendizagem escolar [BOURDIEU, 1979]. ([Helal 2005], p. 7) afirma que "indivíduos socializados em lares cujos pais têm níveis educacionais/culturais mais elevados e posições ocupacionais de maior destaque levam vantagem no mercado de trabalho em relação àqueles cujos pais possuam menor nível de escolaridade e posição ocupacional inferior".

Diante das concepções que envolvem o Capital Social, Helal (2005) o conceitua pelos seus principais representantes (Bourdieu e Coleman). Utilizando um elemento comum associado por eles a esse tipo de capital: a rede de relacionamentos dos indivíduos. Essa rede é muito utilizada para mostrar a interferência do Capital Social na empregabilidade do indivíduo, uma vez que os seus relacionamentos e sua "participação em grupos e organizações" o mantêm atualizado sobre informações e conhecimentos relativos ao mundo do trabalho, afetando "positivamente a probabilidade desse indivíduo estar empregado" ([HELAL, 2005], p. 9).

A probabilidade de um indivíduo estar empregado contempla elementos, que vão além de credenciais escolares, que estão associadas à posse do diploma. Assim, somam-se à escolaridade do indivíduo e suas origens familiares, envolvendo nível 
educacional, cultural e econômico, além da rede de relacionamentos e experiências profissionais. O conjunto dessas variáveis pode determinar a situação de emprego ou desemprego do indivíduo.

\section{METODOLOGIA}

A natureza da presente pesquisa caracterizou-se como mista (quantitativa e qualitativa), definida por possuir resultados mais abrangentes, além de poder neutralizar vieses dos métodos separados e poder gerar a triangulação dos dados por meio da convergência dos métodos qualitativos e quantitativos [CRESWELL, 2007].

A principal estratégia de investigação utilizada no presente estudo foi a pesquisa de survey (levantamento), que através de uma amostra significante de uma população pode-se ter estimativas sobre a população total [BABBIE, 1999].

Os participantes do estudo foram os egressos do CST em ADS dos Institutos Federais no Estado de Minas Gerais, nos anos de 2006 até 2013. O universo da pesquisa configurou-se num total de 311 egressos. Destes, 122 são do IFNMG - Campus Januária; outros 99 do IFTM - Campus Uberaba e 90 do IFMG - Campus Bambuí. Vale ressaltar que a justificativa para a escolha dos referidos campi foi devido ao fato de serem os únicos em Minas Gerais que tinham egressos de CST em ADS no período estudado e por pertencerem a Institutos Federais distintos.

Na pesquisa, o intervalo de coleta de dados ocorreu de outubro a dezembro de 2014. Ou seja, como os egressos são de 2006 até o final do ano de 2013, esses ex-alunos possuem no mínimo um ano de formação.

Para o cálculo da amostra, foi utilizado o método para estimação de proporções para populações finitas, conforme [Bolfarine and Bussab 2005].

Como o CST em ADS nos Institutos Federais Mineiros, que possui egressos, encontra-se em três campi diferentes, com um quantitativo de egresso diferente em cada lugar, foi realizada, em seguida, uma alocação proporcional da amostra por campus. Ou seja, quanto maior o quantitativo de egressos no campus maior o percentual desse campus na amostra.

A amostra utilizada foi de 193 egressos, respeitando a proporção de cada campus, definido a partir da margem de erro $5 \%$ e o nível de significância de $5 \%$.

Vale ressaltar que o método de seleção dos participantes para responderem ao questionário foi o aleatório, todos tiveram a mesma probabilidade de responder ao questionário [BABBIE, 1999]. Já a quantidade de entrevistas semiestruturadas para a pesquisa qualitativa foi de nove egressos (três em cada instituição) escolhidos por conveniência. Foram eles: os ex-alunos que trabalhavam como empregados com carteira assinada; funcionários públicos e autônomos/proprietários de empresas.

\section{ANÁLISE DOS DADOS E RESULTADO}

Analisando o índice de empregabilidade dos tecnólogos do CST em ADS de todos os Institutos Federais de Minas Gerais que possui egresso do referido curso, por meio do gráfico 1, observa-se que, no campus de Bambuí, 89,1\% dos egressos do referido curso encontram-se trabalhando ou trabalhando e estudando, no campus de Januária, esse percentual sobe para $94,8 \%$, já no campus de Uberaba, encontra-se o maior percentual, 
98,3\% de analistas de sistemas exercendo suas atividades profissionais dentro do mercado de trabalho.

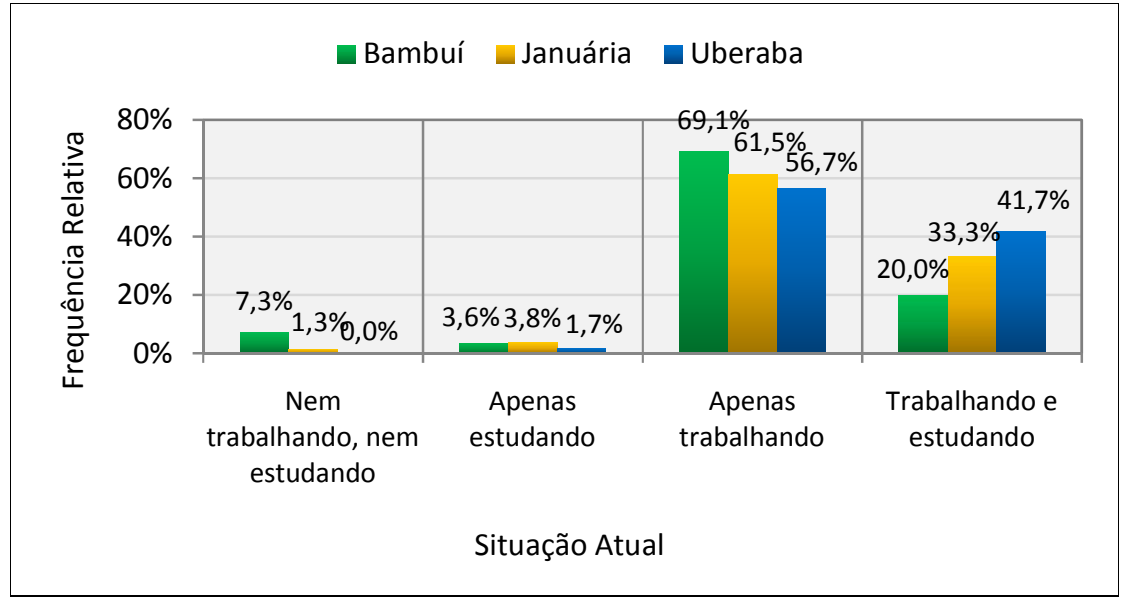

Gráfico 1: Distribuição da situação atual dos entrevistados por campus

Fonte: dados da pesquisa.

Ressalte-se, ainda, que, de forma geral, o índice de ocupação dos tecnólogos também foi satisfatório, dos 193 egressos participantes da pesquisa, 182 deles estavam trabalhando, ou seja, 94,3\% da amostra total.

Procurou-se evidenciar, também, neste estudo, por meio do gráfico 2 a seguir, se as atribuições direcionadas ao tecnólogo, em seu local de trabalho, estão relacionadas à sua formação.

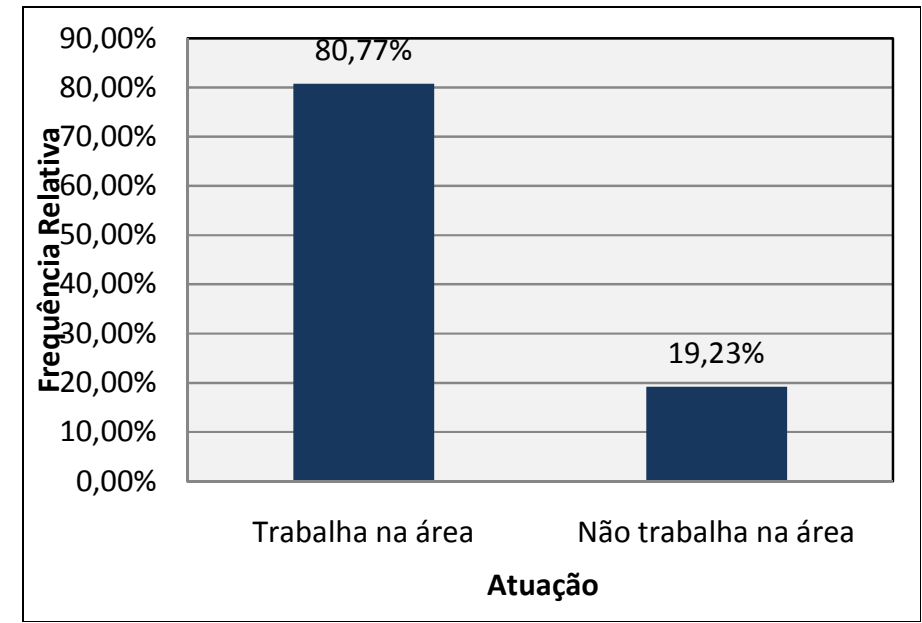

Gráfico 2: Proporção de egressos que afirmaram trabalhar ou não na área de informática

Fonte: dados da pesquisa.

Os dados quantitativos encontrados permitem dizer que, do conjunto total da amostra de ex-alunos dos três institutos federais estudados, quase $81 \%$ exercem suas atividades profissionais em área relacionada com a sua formação, ou seja, informática. Embora muitos deles, realizem, em seu local de trabalho, outras funções paralelas às do tecnólogo, como as pertinentes ao técnico de informática. 

qualitativa.

Essa realidade torna-se perceptível no relato dos egressos, durante a entrevista

[...] minhas atribuições estão relacionadas com a área de informática, só que o meu cargo lá é de técnico em informática, [...] eles me colocaram para trabalhar com a parte de redes. Então no curso de Análises teve a disciplina de redes, mas assim, no geral, o meu trabalho mesmo é de técnico. (Entrevistado U1).

No meu cargo especificamente, acaba que eu exerço outras funções, além das próprias do tecnólogo. [...] eu tenho que mexer com contas, por exemplo, coisas que não são específicas do curso, mas que a própria gestão do setor exige. (Entrevistado J1).

Eu mesmo tenho o CST, mas minha carteira é assinada como técnico, [...]. Mas a maioria das coisas que a gente aprende no curso de tecnólogo dá pra colocar em prática. (Entrevistado J2).

Outra informação interessante, obtida na pesquisa, é que a maioria dos egressos não migrou para outros estados após a conclusão da graduação tecnológica, ou seja, $88,71 \%$ exercem suas atividades profissionais em Minas gerais, o estado de origem de seus Institutos Federais.

A tabela 1 especifica, dentro do estado de Minas Gerais, as mesorregiões onde os egressos realizam seus trabalhos.

Tabela 1: Locais, por Mesorregião do estado de Minas Gerais, onde o egresso realiza o trabalho principal

\begin{tabular}{|c|c|c|c|c|}
\hline Mesorregião de Minas Gerais & $\begin{array}{l}\text { IFMG - } \\
\text { Campus } \\
\text { Bambuí }\end{array}$ & $\begin{array}{l}\text { IFNMG } \\
\text { Campus } \\
\text { Januária }\end{array}$ & $\begin{array}{l}\text { IFTM - } \\
\text { Campus } \\
\text { Uberaba }\end{array}$ & Total \\
\hline Noroeste de Minas & $0,00 \%$ & $5,33 \%$ & $0,00 \%$ & $2,15 \%$ \\
\hline Norte de Minas & $0,00 \%$ & $69,33 \%$ & $0,00 \%$ & $27,96 \%$ \\
\hline Vale do Mucuri & $0,00 \%$ & $0,00 \%$ & $0,00 \%$ & $0,00 \%$ \\
\hline Jequitinhonha & $0,00 \%$ & $4,00 \%$ & $0,00 \%$ & $1,61 \%$ \\
\hline Triângulo Mineiro / Alto Paranaíba & $15,39 \%$ & $2,67 \%$ & $89,83 \%$ & $33,87 \%$ \\
\hline Central Mineira & $7,69 \%$ & $0,00 \%$ & $0,00 \%$ & $2,15 \%$ \\
\hline Metropolitana de Belo Horizonte & $9,62 \%$ & $8,00 \%$ & $0,00 \%$ & $5,92 \%$ \\
\hline Vale do Rio Doce & $0,00 \%$ & $0,00 \%$ & $0,00 \%$ & $0,00 \%$ \\
\hline Oeste de Minas & $49,99 \%$ & $0,00 \%$ & $0,00 \%$ & $13,98 \%$ \\
\hline Sul/Sudeste de Minas & $0,00 \%$ & $0,00 \%$ & $0,00 \%$ & $0,00 \%$ \\
\hline Campos das Vertentes & $3,84 \%$ & $0,00 \%$ & $0,00 \%$ & $1,08 \%$ \\
\hline Zona da Mata & $0,00 \%$ & $0,00 \%$ & $0,00 \%$ & $0,00 \%$ \\
\hline TOTAL & $86,54 \%$ & $89,33 \%$ & $89,83 \%$ & $88,71 \%$ \\
\hline
\end{tabular}

Fonte: dados da pesquisa. Nota: grifos nossos.

Assim, fica evidente que parte significativa dos tecnólogos está trabalhando na mesorregião onde fez o curso. Praticamente 50,0\% dos tecnólogos egressos do Campus de Bambuí ocupam postos de trabalho na região Oeste de Minas, onde se localiza o referido campus. Em Januária, mais de 69,0\% atuam também em torno da origem do instituto, ou seja, no Norte de Minas. Ressalta-se que a Mesorregião do Triângulo Mineiro/Alto Paranaíba foi a que mais reteve seus graduados; todos os egressos do Campus de Uberaba que permaneceram em Minas Gerais exercem suas atividades profissionais nessa localidade. 
Verifica-se, conforme dados da pesquisa, que a média salarial entre os três institutos é semelhante. Há discrepância, todavia, quando se compara a renda mensal dos egressos com a média de remuneração da mesorregião onde eles estão inseridos. Conforme mostra a tabela 2, percebe-se que, apesar de o campus de Uberaba ter se destacado pelo seu baixo índice de desemprego, apenas $1,7 \%$, por ser a mesorregião que mais emprega os seus egressos (quase $90 \%$ ) e a que apresenta a maior média salarial para o nível superior de ensino ( $\mathrm{R} \$ 3.696,48)$, em comparação à de outros institutos incluídos na pesquisa, representou o menor percentual, 55\%, de egressos que recebem dentro da média salarial da mesorregião ou acima dessa. Em seguida, aparece Bambuí com $58,1 \%$ e Januária com $60,3 \%$ de egressos, recebendo dentro ou acima da média de sua mesorregião.

Tabela 2: Mesorregiões de Minas Gerais - Remuneração média, de dezembro de 2013, segundo graus de instrução superior completo e gênero - 2013

\begin{tabular}{l|ccc|cccc}
\hline \multirow{2}{*}{ Mesorregião } & \multicolumn{3}{|c|}{ Ensino Médio Completo } & \multicolumn{3}{c}{ Superior Completo } \\
\cline { 2 - 7 } & Masculino & Feminino & Total & Masculino & Feminino & Total \\
\hline Norte de Minas & $1.255,81$ & 982,22 & $1.131,16$ & $3.667,16$ & $2.376,03$ & $2.810,49$ \\
\hline $\begin{array}{l}\text { Triângulo } \\
\begin{array}{l}\text { Mineiro/Alto } \\
\text { Paranaíba }\end{array}\end{array}$ & $1.789,90$ & $1.200,65$ & $1.521,00$ & $4.882,04$ & $2.936,64$ & $3.696,48$ \\
\hline Oeste de Minas & $1.488,48$ & $1.078,35$ & $1.282,73$ & $3.658,26$ & $2.315,01$ & $2.775,72$ \\
\hline Total - MG & $1.882,73$ & $1.220,56$ & $1.579,31$ & $5.900,47$ & $3.423,69$ & $4.364,94$ \\
\hline
\end{tabular}

Fonte: RAIS - Dec. 76.900/75.

\section{Nota: elaborado por CGET/DES/SPPE/MTE}

Considerando o fato de que parte significativa dos tecnólogos desta pesquisa estava trabalhando, principalmente em sua área de formação, conforme mostrado anteriormente, e que atuam na região de abrangência dos seus respectivos institutos federais, afirma-se que o CST em ADS, dos Campi que fazem parte desta investigação, foram implantados seguindo um critério de planejamento, organização e funcionamento voltado para o "atendimento às demandas do cidadão, do mercado de trabalho e da sociedade", bem como às demandas peculiares de suas regiões, de acordo com o que foi instituído pelas Diretrizes Nacionais Gerais para a organização e funcionamento dos Cursos Superiores de Tecnologia por meio da Resolução CNE/CP n ${ }^{\circ} 3$, de 2002 e por [Bastos 1991].

Como estudos indicam a influência do capital econômico na empregabilidade, como relatado anteriormente, pesquisamos se o referido capital poderia ter influência na escolha do CST em ADS nos IFs mineiros, através de um levantamento dos principais motivos de escolha.

A gratuidade foi, entre os fatores de justificativa de escolha, o que mais se destacou na entrevista qualitativa.

\footnotetext{
$\mathrm{Na}$ época que eu fiz o curso, a primeira opção foi porque era um curso público, não era particular, eu não tinha condições financeiras de bancar um curso. (Entrevistado B1).

Como eu estava apertado de dinheiro [...], fui obrigado a escolher uma coisa mais perto que no caso era aqui no IFMG e entre os cursos que tinham no instituto, na época, esse [Análise e Desenvolvimento de Sistemas] era o que tinha mais sintonia com o meu perfil . (Entrevistado B3).
} 
O motivo que mais influenciou a minha entrada tanto no curso técnico como no superior foi a oferta gratuita dos cursos; segundo por causa da minha dificuldade de sair da cidade. (Entrevistado J2).

O principal explicador de demanda para a escolha do CST, também, na pesquisa quantitativa, se relaciona-se com as condições econômicas dos egressos, na época do ingresso no ensino superior. Como apresentado no gráfico 3, que nos mostra a ordem de classificação desses fatores

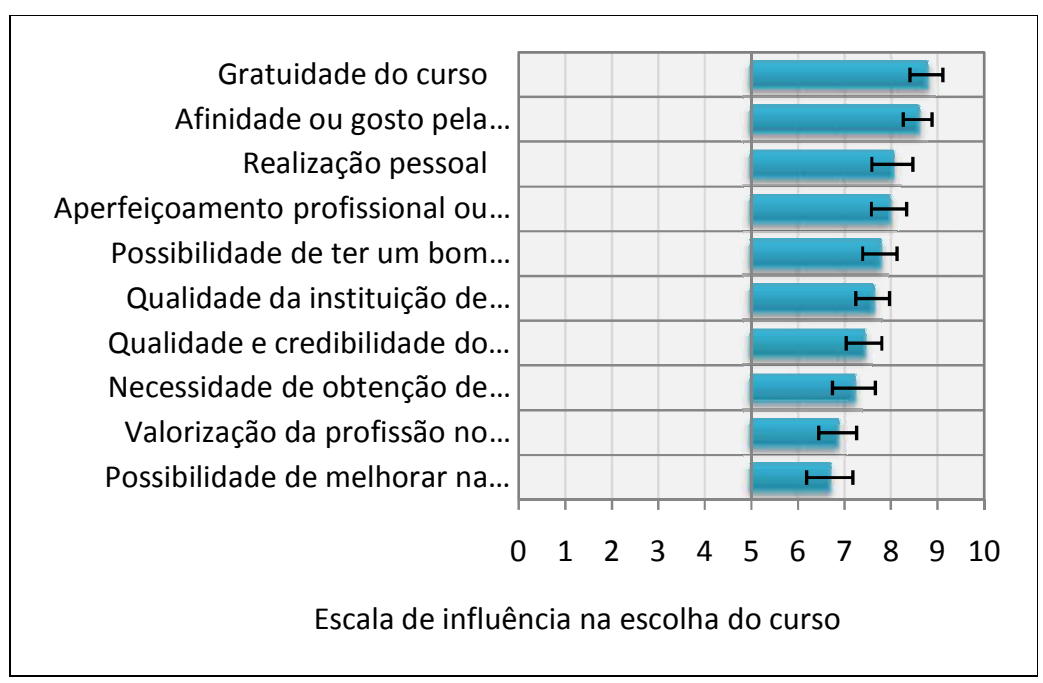

\section{Gráfico 3: Média da escala de influência para os dez itens mais importantes para a escolha do CST}

\section{Fonte: dados da pesquisa.}

No que concerne à afinidade ou gosto pela área/profissão (segundo principal motivo de escolha), conforme apresenta o gráfico 4, observa-se que cursar o técnico em informática no nível médio de ensino pode ser considerado um dos fatores responsáveis por ter despertado nos egressos o interesse pelo CST em ADS, principalmente, por meio da descoberta da afinidade pela área do curso.

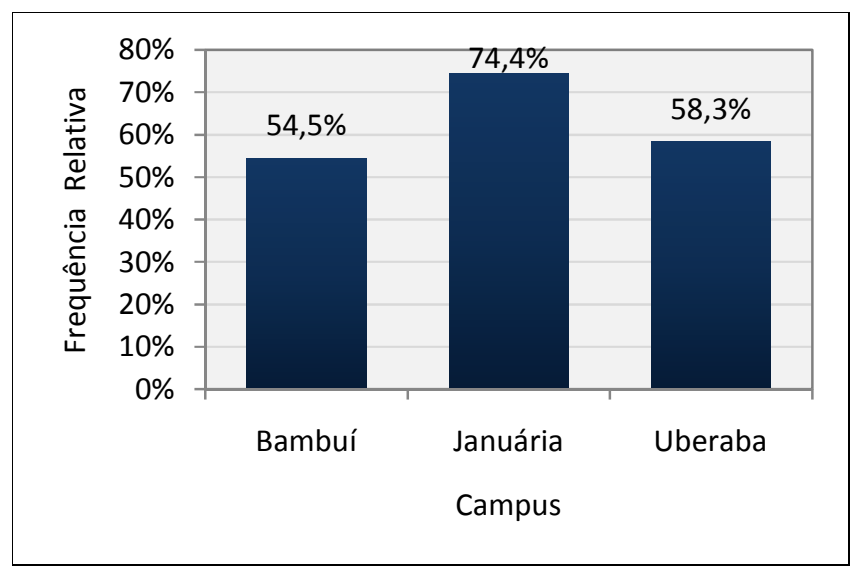

Gráfico 4: Proporção de egressos que afirmaram ter realizado curso técnico de nível médio na área de informática

Fonte: dados da pesquisa. 
Nota-se, também, na entrevista qualitativa, que os egressos reafirmam que essa afinidade pela área surgiu com a conclusão do curso técnico como mostrado nos depoimentos a seguir:

Eu escolhi o curso porque, primeiramente, eu iniciei aqui fazendo o curso técnico de informática,[...] gostei da área e decidi fazer o curso superior aqui mesmo. (Entrevistado B2).

[...] já tinha feito curso técnico no IF do Triângulo Mineiro - Campus Uberaba. Gostei do curso técnico e quis dar prosseguimento com o curso superior. (Entrevistado U1).

O que influenciou na verdade foi eu ter feito o curso técnico em informática. Ainda durante o curso, eu comecei a trabalhar com informática, comecei a gostar da área, então, queria dar prosseguimento na carreira com o curso superior. (Entrevistado J1).

Esses achados corroboram com os do estudo de Andrade (2009), que deixa subtendida a tendência dos técnicos de buscar uma diplomação que se relacione com a área na qual já tenham desenvolvido alguma competência.

Para analisar a influência do capital humano, cultural e social nas maiores remunerações dos egressos, selecionaram-se todos os egressos que possuíam algum trabalho remunerado na época do levantamento. Em seguida, utilizou-se uma regressão logística e o método de Stepwise [AGRESTI, 2002]. Visto que, para o procedimento de Foward (critério de entrada das variáveis na análise de regressão), foram selecionadas as variáveis que poderiam ter alguma influência nessa renda. Assim, utilizou-se as variáveis referentes ao: a) perfil do egresso envolvendo: gênero, localização do trabalho, cor/raça, estado civil, possuir filho, tipo de ensino fundamental e médio, idade na época em que concluiu o curso; b) capital cultural: foram utilizadas as variáveis relativas ao background familiar como: escolaridade do pai e da mãe e a renda média familiar; c) capital social referindo-se às vias utilizadas para conseguir emprego (como conseguiu o emprego); d) capital humano, sondagem se o egresso possuía ou não o curso técnico, tempo de formado, tempo de experiência, se continuou ou não os estudos.

Após ajustar a regressão logística múltipla e aplicar o método Backward, verificou-se que o gênero, a escolaridade do pai, a renda média familiar, a idade, o tempo de formado e o tempo de experiência exerceram influência significativa no que se refere ao egresso ter um rendimento maior que 6 salários mínimos. Dessa forma, ao analisar cada uma das variáveis citadas anteriormente, em separado e, controlar as demais, conclui-se que existe uma preponderância do egresso do gênero masculino receber os maiores salários. Assim, as chances de um homem receber acima de 6 salários é superior a das mulheres 33,09 vezes. Esse dado vai ao encontro ao apresentado por Gentili (2002), em que o autor destaca outros fatores associados à empregabilidade, que podem representar um diferencial nos processos seletivos fornecedores de emprego e renda, ou seja, "ser branco, ser negro, ser imigrante, ser gordo, ser surdo, ser nordestino..." ([GENTILI, 2002], p. 55). O caso particular "ser mulher', como demonstra os dados da regressão, ainda implica ter menos chances de receber os maiores salários. Vale ressaltar, que os maiores salários não necessariamente são para aqueles que atuam na informática (apesar da maioria atuarem nessa área).

Do mesmo modo, os tecnólogos egressos cujos pais concluíram o ensino médio apresentam quatorze vezes mais chances de receber acima de 6 salários em relação aos tecnólogos cujos pais não concluíram o ensino médio. Essa constatação mostra-nos a importância do capital cultural na empregabilidade. 
Um achado interessante relaciona-se ao capital cultural, no que se refere à renda familiar. Este estudo mostrou que os egressos provenientes de famílias com renda mensal superior a 6 salários mínimos têm mais chances, cerca de 126 vezes, de receberem uma renda igual ou superior a essa em relação àqueles cujos pais têm renda menor que a especificada, ou seja, quanto maior o nível salarial de sua família de origem, maiores são as chances do egresso adquirir melhor remuneração no mercado de trabalho.

Outro fator de importante destaque na investigação é que o capital humano, referente ao investimento nos estudos, não causou influência significativa quanto ao nível salarial. Vale ressaltar que os egressos do curso estudado, mesmo associando outros títulos à graduação, como uma pós-graduação, não influenciou para a obtenção de um rendimento mensal superior a 6 salários mínimos.

As variáveis tempo de formado, tempo de experiência e migração (quantidade de empregos), consideradas derivações do capital humano, exerceram influência positiva para o aumento de chances dos egressos receberem acima de 6 salários: em 2,88 vezes para cada ano que se aumenta no tempo em que este adquiriu a titulação; 1,43 vezes para cada ano a mais de experiência; 1,92 vezes para cada emprego a mais que eles têm.

O capital humano continua a influenciar para as maiores remunerações, no caso estudado de 6 salários mínimos, porém, essa influência para os que já possuem o curso superior, como na presente pesquisa, não aconteceu com o investimento na continuação dos estudos e sim nos outros fatores relacionados ao capital humano, como demonstrado: tempo de formado, tempo de experiência e quantidade de empregos.

As variáveis cor/raça e o fato de ser branco não mostraram diferença no estudo, nem no ingresso no mercado, nem nas maiores remunerações. Em contrapartida, conforme demonstrado, os tipos capitais, principalmente o capital humano e cultural, fazem toda diferença na obtenção dos maiores salários.

\section{CONSIDERAÇÕES FINAIS}

Realizadas a investigação e a comparação da situação profissional dos egressos do CST em ADS, afirma-se que o índice de empregabilidade desses egressos, nos três institutos federais mineiros que participaram da pesquisa, é alto. Principalmente quando os resultados quantitativos revelaram que $94,3 \%$ da amostra total estavam trabalhando no momento da aplicação do questionário.

A maioria dos egressos está atuando no mercado de trabalho das mesorregiões que envolvem sua origem institucional. Tal situação deixa subentender que houve, por parte das instituições, uma aproximação com o setor de produção, no sentido de conhecer os arranjos produtivos locais, antes de implantarem o curso analisado, pois pelo que já foi apresentado, no decorrer da pesquisa, as demandas do mercado de trabalho regional, em particular do aluno e da sociedade, foram atendidas com a oferta do CST em questão.

Outra constatação é a de expressivo quantitativo de participantes deste estudo, que associou a escolha do CST em ADS às suas condições financeiras, reafirmando que a Educação Profissional e Tecnológica se configurou na principal via de expansão das possibilidades de acesso à educação superior, para os filhos de trabalhadores desprovidos de nível econômico de grandes representações, que também escreveram sua 
trajetória educacional em escolas públicas e, em sua maioria, não tiveram a oportunidade de ir além do nível médio de ensino.

Por fim, pode-se afirmar a grande influência que o capital humano, cultural e social tem sobre a empregabilidade. Tendo em vista, por exemplo, que para os egressos do CST em ADS nos IFs estudados, quanto maior o ensino e a renda dos pais (capital cultural), maiores são as chances dos egressos receberem os melhores salários, o mesmo acontece em relação ao capital humano, quanto maior o tempo de formado e o número de empregos, maiores são as chances do egresso receber os maiores salários.

\section{REFERÊNCIAS BIBLIOGRÁFICAS}

AGRESTI, A. Categorical data analysis.New York: Wiley, 2002.

ANDRADE, Andréa de Farias Barros. Cursos superiores de tecnologia: um estudo de sua demanda sob a ótica dos estudantes. 2009. 152f. Dissertação (Mestrado em Educação) - Faculdade de Educação Programa de Pós-Graduação em Educação. Universidade de Brasília, Distrito Federal, 2009.

BABBIE, E. Métodos de pesquisa de survey. Belo Horizonte: Editora UFMG, 1999.

BASTOS, João Augusto de Souza Leão de Almeida. Cursos superiores de tecnologia: avaliação e perspectivas de um modelo de educação técnico profissional. Brasília: SENETE, 1991.

BOLFARINE, H.; BUSSAB, W. O. Elementos de amostragem. São Paulo: Blucher, 2005.

BOURDIEU, P. Os três estados do capital cultural. In: NOGUEIRA, M. A.; CATANI, A. (Org.). Escritos de educação. Petrópolis: Vozes, 1979. p. 73-79.(3. ed. 2001).

BRASIL. Parecer CNE/CP $\mathrm{n}^{\circ}$ 03, de 03 de dezembro de 2002. Institui as Diretrizes Curriculares Nacionais Gerais para a organização e o funcionamento dos cursos superiores de tecnologia. Diário Oficial da República Federativa do Brasil, Brasília, DF.

CRESWELL, J. W. Projeto de pesquisa: métodos qualitativo, quantitativo e misto. 2. ed. Porto Alegre: Artmed, 2007.

GENTILI, P. Três teses sobre a relação trabalho e educação em tempos neoliberais. In: LOMBARDI, José Claudinei; SAVIANI, D.; SANFELICE, José Luís (Org.). Capitalismo, trabalho e educação. Campinas: Autores Associados; HISTEDBR, 2002. Parte II, Estudo Três. p. 45-59.

HELAL, D. H.. Flexibilização organizacional e empregabilidade individual: proposição de um modelo explicativo. Cad. EBAPE.BR, Rio de Janeiro, v. 3, n. 1, mar.2005.

RAIS, Relação Anual de Informações sociais. www.acessoainformacao.gov.br

SCHULTZ, T. W.. O capital humano: investimento em educação e pesquisa. Rio de Janeiro: Zahar Editores, 1973. 